\title{
COVID 19 - The Swiss Perspective
}

\author{
Juri Sromicki ${ }^{1}$, Martin Schmiady ${ }^{1}$, Francesco Maisano $^{2}$, and Carlos Mestres $^{2}$ \\ ${ }^{1}$ UniversitatsSpital Zurich \\ ${ }^{2}$ University Hospital Zurich
}

July 31, 2020

\begin{abstract}
The current COVID-19 pandemic has a huge impact on society and economy and represents one of the biggest challenges for healthcare systems all over the world. Reports from health-care-institutions in different countries show a variety of crisis exit strategies. Although experiences in handling of the pandemic have accumulated over the last 7 months, it is clear that measures to prevent a collapse of the health-care-systems have to be adapted to local political and socioeconomic structures. The aim of this review is to give insight in crisis exit strategies in Switzerland, highlighting the role and impact of COVID-19 in the field of cardiac surgery.
\end{abstract}

\section{Key words}

COVID-19, cardiac surgery, Switzerland

\section{Introduction}

The recent history of Coronavirus disease 2019 (COVID-19) [1]. At the end of February 2020, COVID19 disease hit Europe with worst impact on Italy's northern regions. On February 28, the Italian Civil Protection Bulletin confirmed 531 cases with 21 deaths [2].

In Switzerland, the first COVID-19 case was confirmed on February 25 [3]. Within a week, the virus was spread all over the country and cases were reported from different Cantons [4]. The World Health Organization (WHO) declared COVID-19 a pandemic on March 11, pointing to 118,000 cases in over 110 countries and the sustained risk of further global spread [1]. This had obvious impact on local and national clinical and academic activities all over Switzerland. Immediate challenges were evident. Nobody was initially ready for this.

On February 28, the Swiss Federal Council, categorized the situation in Switzerland as "special" [5], in terms of the Epidemics Act, in force since \sout01.01.2016 January 1, 2016 [6]. Events involving more than 1,000 people were banned with immediate effect. An "extraordinary situation" was declared by the Swiss Federal Council on March 16 also in terms of the Epidemics Act. All shops, restaurants, bars and entertainment and leisure facilities had to remain closed. As of midnight that day, checks on the borders to Germany, Austria and France were introduced. The Federal Council authorized the deployment of up to 8,000 members of the Armed Forces to assist the Cantons at hospitals and with logistics and security [7]. Following strict observance of measures at the national level, the Swiss Federal Council declared that on April 27, hospitals could resume all medical procedures, including non-urgent procedures, and outpatient medical practices, with the proviso that protection of the public and of staff must be assured. The declaration aimed at helping people and businesses to plan by announcing its schedule for the further easing of lockdown measures up to the start of June [8].

There was immediate local reaction on February 28. Contingency plans were devised to tackle the sudden unexpected disruption of activities. The University Hospital of Zürich (USZ) established a specific Task 
Force led by the Hospital CEO. The Task Force established mandatory basic hygiene measures, including different types of personal protection equipment (PPE) in relation with different levels of patient care. USZ staff was instructed to follow the recommendations issued by the Regional Healthcare Department. Homework policies were issued. USZ cancelled all already scheduled national and international academic activities entailing close interpersonal contact. Attendance to scientific events, national and internal, was forbidden. All elective operations and procedures were postponed on March 16, as per the Federal Council declarations. Academic activities were therefore heavily affected. There was appropriate reaction as recently described [9].

The Swiss Federal Office for Public Health (BAG) daily updated data on confirmed cases of COVID-19 and deaths due to infection, the national epidemiological situation, the information on contact tracing, search for antibodies and communication strategies on its website [4]. The BAG relied on the cantonal authorities for tracing transmission. At the time of writing this contribution on July 19, 2020 the BAG has registered 33,431 confirmed cases with 1,687 registered COVID-19 deaths, for a 5.0\% death rate. This data summarize the epidemiological situation in Switzerland and the Principality of Liechtenstein [10].

There has been massive impact of COVID-19 on the society. Switzerland had one of the highest number of infections per capita in the world during the initial wave, as reported by Salathé et al. [11]. In the middle of March 2020, the authors confirmed that operational challenges, rapid and determined prevention of transmission while minimizing the damage to the health of the population were the objectives of testing, contact tracing and isolation [11]. The following summarizes the impact of COVID-19 on cardiac surgery.

\section{Crisis-Management in Switzerland / Zurich}

\section{Demographics and Healthcare}

Switzerland is a country of 8.6 million inhabitants [12] in the heart of mainland Europe. Surrounded by members of the European Union (EU), despite all contractual obligations, from legal standpoint the country is technically independent of the EU and therefore not subject to the EU-law per se. Divided into 26 Cantons, the principle of federalism is deeply enshrined in the political system. It allows every Canton to issue own decrees legally binding within its border. The country's highest executive authority is vested in the Federal Council (Bundesrat), a panel of 7 representatives forming the government of Switzerland. The legal framework on planning and acting in case of a pandemic is adopted in the law on Epidemics (6) transferring full executive, legislative and judicial power to the Federal Council to issue nationwide regulations on top of cantonal decrees. The well-structured political system, federalist concept and short information chains and distances across the country all contribute to Switzerland being a country known for its good organization, an important prerequisite for successful crisis management.

There are 1.6 million inhabitants (18.7\%) in Switzerland over 65 years of age, a risk population for COVID-19 infections. Around $29.6 \%$ of deaths in the male and $33.1 \%$ in the female population have a cardiovascular origin [13]. The healthcare system is based on a compulsory health insurance. As of 2018, Switzerland had 281 hospitals, 102 of them providing general healthcare to the public [14]. Five Hospitals (Zurich, Berne, Basel, Geneva, Lausanne) are instituted by a University and are considered tertiary hospitals.

Currently, 16 centers do perform cardiac surgery in Switzerland, with three covering the full range of surgical procedures including heart transplantations. A few hospitals have a well-established extracorporeal membrane oxygenation (ECMO) program. Hosting the Transplant- and Mechanical-Support-Program in the northeastern part of Switzerland, USZ is known to have a broad expertise in ECMO therapy including airbound interhospital transfer of critically ill patients [15]. In 2015 in Switzerland altogether 6,901 patients underwent cardiac surgery [16] with lax national regulations on patient-flow, lack of patient-centralization and high dependency of smaller hospitals on personal referrals.

\section{Adaptation to measures}

The first confirmed COVID-19 case in Switzerland was reported in the Canton of Tessin by the the Italian border. At that time, Italy had 322 cases [17] although assumingly many cases were unreported yet due to 
restrictive COVID-testing in the early phase of the pandemic. Close economical and working relationships, including cross-border commuters traveling back and forth all contributed to an early and rapid dissemination of COVID-19 in Switzerland. For the first five days, all positive results in Switzerland could be retraced to a physical contact with people from the northern part of Italy. In a week, the numbers in Switzerland increased rapidly. Most of the new infections thereafter were gathered within the own national borders.

Long before WHO declared the pandemic, the Swiss Federal Office of Public Health (Bundesamt für Gesundheit - BAG/FOPH) took measures to protect its citizens and prevent a collapse of the national healthcare system. Surely, the federalist political system and trust of the Swiss people in the national healthcare system has proven to be helpful in that matter. By keeping the transmission paths for official instructions short, running national campaigns in TV and on billboards, a continuous flow of information was ensured to all socioeconomic classes.

The first official measures included a close control of people travelling from COVID-hotspots and filling storages for protective medical gear to the best possible extent. Plans and strategies for an imminent lockdown were discussed early on. The border to the southern neighboring country was closed by March 11, 2020 when 1,168 people were reported to be tested positive for COVID-19 in Switzerland and 12,462 in Italy[17, 18]. By decree of the Federal Council from March 17, 2020 on most retailers, public buildings and recreational parks remained closed and mandatory physical distancing was implemented putting local law enforcement in charge to transpose that law. Employees were asked to stay at home whenever possible and recommendations on working from home were given. Controversially discussed, as still unknown to what extent kids and younger people contribute to a rapid spread of the virus, schools and Universities, kindergartens and most daycare facilities for children also closed their doors during the peak incidence of COVID-19. Elective surgery was banned from March 17 on. Only operations where a delay might lead to a shortening of life expectancy, permanent damage, worsening of the clinical status or if postponement was associated with severe impact in life-quality were allowed. In Switzerland there are 38,000, hospital beds with around 1,000 beds in 82 Intensive Care Units (ICU) [19]. Under pressure of the expected COVID-19 crisis, the healthcare providers in Switzerland succeeded to increase the number of ICU beds up to 1,500 by closing operating theatres, reopening ICU wards, buying and reactivating outsourced ventilators.

By the end of April, Switzerland had 30,000 patients tested positive for COVID-19, one of the highest incidences worldwide (up to 1,500 new infections per day, i.e. 17/100,000 inhabitants) surpassed only by Hubei province in China, Italy and later on the pandemic spread in Spain and the US. Despite all fears, the healthcare system in Switzerland did not collapse under the first flood of patients. Since SARS-CoV-2-tests were not widely available at that time, the initial strategy intended testing of vulnerable patients $(>65 \mathrm{y}$ of age) and patients requiring hospitalization only [11]. This testing strategy limited the assessment of the overall COVID-burden, allowing no statement on prevalence or asymptomatic infections, but surely led to a proper identification of patients in need for hospitalization or immediate medical care. Switzerland has a reasonably high physician density of 4.4 doctors per 1,000 inhabitants but not higher than the surrounding countries (Germany: 4.2, Austria 5.1, Italy 4.0, France 3.2) [20]. What may be different is the role of the primary care physician (PCP) in the national healthcare system. Most PCPs in Switzerland are organized in a network, have a close accountability for their patients and are capable to do a first-line screening for patients with potential COVID-19 infection. The highly structured PCP-network prevented an overload of patients in the secondary and tertiary hospitals allowing them to focus on sick patients. The main involvement of cardiac surgery was in treatment of COVID-19 patients when they needed ECMO support. The following section will focus on that. No patient underwent cardiac surgery on an urgency or emergency setting with an ongoing COVID-19 infection at our Department during the first wave.

The healthcare system in Switzerland never collapsed. The first couple of weeks, hospitals faced shortness of protective medical gear, especially in the southern part of Switzerland, one of the first hotspots. The government supported the healthcare facilities with medical supplies and required equipment was flown in before partial lockdown. Shortness on staff was overcome with short-term employment of medical students, supportive care for supply-chains etc. came from 8,000 armed forced. 
By April 27, 2020 the federal council started to stepwise ease down on the lockdown measures allowing retailers to reopen again and people to meet in smaller groups. For two months, the number of new infections remained low until the incidence started to increase again at the end of June. Immediate countermeasures were taken, now obliging commuters to wear facemasks in the public transport. Since the numbers did not grow far beyond 100 new infections per day and backtracking mechanisms were implemented for public gatherings, there is hope, that a second wave can be averted without going into a second lockdown and another economic crisis.

By July 19, 2020 out of 726,806 tests performed in Switzerland, 33,431 were reported to be positive for COVID-19 (4.6\%), leading to 1,687 deaths so far. None of our fellow co-workers in the clinic for cardiac surgery was infected with COVID-19. Fifty-three out of 8,480 hospital employees were tested positive. Most of those employees reportedly had no contact to COVID-19 patients. Not a single infection could be traced back to an in-hospital contact with an infected patient, proving protective measures to have worked effectively. Overall, 143 patients with COVID-19-infections had to be hospitalized in the USZ, 130 had a successful recovery, $12(8.4 \%)$ deaths were reported.

\section{Change in Surgical Volume and Treatment strategies}

The USZ runs a Cardiac Surgery-Program, currently performing about 850 open surgeries and 350 transcatheter interventions yearly. During the peak of the COVID-19-pandemic in Switzerland elective surgery in our institution was banned from March 1660 April 27 until 27.04.2020. During that time-period, cardiac surgery was performed exclusively on an urgency or emergency basis. A total of 51 major operations, 26 structural interventions and 38 other procedures were performed under the accountability of our clinic during this 6 -week period following federal and institutional recommendations. Strikingly the number of structural interventions did not significantly drop when compared to the previous years. Comorbidities and an average age of 77 years all contributed to those patients to be meeting the criteria for an intervention under a non-elective setting (shortening of life expectancy, worsening of the clinical status, permanent damage, hospitalization). With careful selection, patients referred for structural interventions seem to be less susceptible for special regulations on the elective program. Postponement of such interventions is often associated with a shortening of an anyway limited life expectancy and in case of low complication rates, patients treated with modern minimally invasive concepts seldom need critical resources of an ICU [21].

\section{ECMO in COVID}

\section{Extracorporeal Membrane Oxygenation for COVID-19 Disease: The Zürich Experience}

At the time of the first confirmed COVID-19 case in Switzerland, our department was equipped with 8 ECMO devices and 20 oxygenators. USZ put together a task force to analyze the situation and take appropriate precautions. The institutional decision was made to purchase 12 new ECMO devices, in order to be prepared for an uncertain number of critically ill patients. Two weeks later, our warehouse contained 23 ECMO devices, 150 oxygenators and more than 300 different cannulas. On March 28, 2020, the first V-V ECMO for a COVID-19 patient with severe hypoxia, refractory to invasive ventilation, was implanted by us. With reference to the EuroELSO ECMO-COVID-19 Survey, 20 ECMOs have been implanted in Switzerland (9 USZ Zürich, 6 CHUV Lausanne, 3 Inselspital Bern, 2 Basel) during the COVID pandemic so far [22]. As the register is voluntary, the numbers are likely to be slightly underestimated. Compared to other European countries, the absolute number of ECMO cases in critical ill COVID-19 patients is low in Switzerland. Possible explanations for this can be the low overall population, the early lock down, which successfully limited the spread of the virus but also a critical patient selection.

During end of March and May 2020, ECMO was necessary in 9 critically ill COVID-19 patients: 6 were supported with V-V ECMO and 3 with V-A ECMO configurations. Three of these 9 ECMOs were implanted in an external hospital. After successful implantation, the patients were transported to our center in a helicopter on safe ECMO support during the flight. All patients had severe, rapidly progressive acute respiratory distress syndrome (ARDS). One patient suffered from pulmonary artery embolism, which worsened the respiratory situation before ECMO implantation. In the further course the patient was diagnosed with 
heparin induced Thrombocytopenia (HIT) [23]. Three patients required V-A ECMO support due to a septic condition with myocardial involvement. Seven patients could be weaned successfully from ECMO support and survived the disease. Two patients died due to intestinal ischemia with severe sepsis. Median age at implant was 59 years (46-69). Patient characteristics are listed in Table 1. All patients were healthy prior to the COVID-19 infection, with only minor comorbidities. An association with previously known diabetes, obesity or pre-existing respiratory diseases (asthma) was found particularly often.

ECMO therapy is a well establish procedure in the USZ and numbers are increasing. With around 150 ECMO implantations per year, our center runs one of the leading national ECMO-programmes also focusing on interhospital transport of patients on ECMO support over the past 10 years [15]. Within the last 6 years, we performed 165 ECMO transports and covered a distance of 22,000 kilometers during these missions.

High quality standards are guaranteed and checked by a regular training and certification program. For this purpose, we developed a simulator on which the operative/percutaneous vascular access and cannulation can be replicated with the original material (Figure 1). The already established infrastructure and team approach, including cardiac surgery, cardiology, anesthesiology and intensive care medicine, perfusionists, critical care and scrub nurses has created a solid foundation for the successful implementation of an ECMO program in the critical field of this global crisis. Previous studies during the Middle Eastern respiratory syndrome (MERS) and H1N1 outbreak report lower mortality and reduced organ failure when ECMO was offered to those, who failed optimal ventilation strategies, compared to the non-ECMO group [24, 25]. The WHO interim guidelines made general recommendations for treatment of ARDS in COVID-19 patients, including referring patients with refractory hypoxemia to expert centers capable of providing ECMO therapy. V-V ECMO can provide respiratory support in critically ill patients and minimize ventilator-induced lung injury, barotrauma and oxygen toxicity.

As patient selection is crucial, and key to success, we implemented an ECMO Evaluation sheet, recording age, height and weight, comorbidities, length of oro-tracheal intubation and actual ventilation parameters, hemodynamics including catecholamine use and infection parameters, in our daily routine. We used the PRESERVE-Score, Murray-Score and Horowitz-Index to assess the indication and expected outcome. In-house indications and contraindications for ECMO in COVID-19 patients, based on the ELSO recommendations, were established and interdisciplinary discussed before each implantation. The Cardiohelp System (Maquet, Getinge AB, Rastatt, Germany) in combination with an HLS 7.0 oxygenator was used routinely in all patients. For V-V ECMO support we used a femoro-jugular approach (Figure 2). Cannulation was performed bedside in the ICU, using ultrasound-guided femoral/jugular vein/artery puncture. Cannula placement was guided using transesophageal echocardiography (TEE) whenever possible. Avoidance of patient transports to the operating room reduces the risk of COVID-19 transmission to other patients and healthcare providers as well as environmental contamination. For V-V ECMO implantation in COVID-19 patients, we do not recommend the dual lumen cannula, as the implantation and positioning may be challenging and time-consuming, furthermore assuring proper cannula position while proning the patient is highly demanding. ECMO patients should be anticoagulated using regular heparin. As we experienced a prothrombotic state our COVID-19 patients, we kept target activated clotting time (ACT) between 180-200 seconds. Heparin-induced thrombocytopenia should be monitored and treated early. In addition to the reckoned personnel and logistical effort, ECMO centers also face additional challenges in terms of employee protection and safe patient transportation during the COVID pandemic. The standard personal protection equipment (PPE) guidance by Public Health England (PHE) for healthcare workers involved in care of patients with COVID-19, include a disposable apron, gloves, surgical mask and eye protection [26] (Figure 3). During ECMO implantation and explantation in the ICU, the whole team is working in a high-risk environment. Especially during TEE, which is used for wire and cannula placement, there is an increased risk of aerosol release. Therefore, it is recommended to wear a protective respirator mask (N99 or FFP3 equivalent, which can be either valved or unvalved) during these procedures. As the standard of PPE may vary between different hospitals, we have put together a compact PPE kit for the protection of our team, which is also used for external applications (Figure 4). 


\section{Conclusions}

COVID-19 has had a devastating impact on society so far. Future consequences are not yet fully quantifiable. In Switzerland, measures to limit the impact of the pandemic were implemented early, which had an impact on controlling the spread of the disease and associated mortality.

The associated restriction of elective surgical activity has had an impact on surgical programs, observing a slow but progressive recovery. In our environment, we have not detected infections from cardiac surgery personnel or surgical mortality associated with infection.

The incidence of ECMO implants in Switzerland has been lower than in other countries. Locally, at USZ, the development of our ECMO program has enabled the implantation and transportation of COVID-19 patients from distant institutions.

\section{Acknowledgements}

We kindly thank Dr. iur. M. Handle, Zurich for critically reviewing the manuscript for legal inconsistencies

\section{Funding}

This study is not funded

\section{Data sharing}

The authors declare that the data collected was gathered from available databases

\section{Declaration of Competing Interest}

The authors declare no conflict of interest with this contribution

\section{Tables}

Table 1

ECMO-Patients characteristics

Figure Legends

\section{Figure 1}

Set-up of our simulator-based ECMO-Training-Program

\section{Figure 2}

Chest-X-Ray of a patient with severe acute respiratory distress syndrome (ARDS) prior to (A) and after V-V-ECMO-Implantation

\section{Figure 3}

Personal protection equipment (PPE) in use during transport of a COVID-Patient on ECMO-support

\section{Figure 4}

Prepacked personal protection equipment (PPE) for ECMO-Implantation

\section{References}

1. WHO - World Health Organization. Webpage of the WHO - World Health Organization2020; www.who.int.

2. Protezione Civile - Presidenza del Consiglio del Ministri Dipartimento della Protezione Civile. Emergenza Coronavirus 2020; www.protezionecivile.gov.it.

3. Blick. Coronavirus breitet sich aus - Erster bestätigter Fall in der Schweiz 2020; https://www.blick.ch/news/coronavirus-erster-bestaetigter-fall-von-coronavirus-in-der-schweizid15767285.html. 
4. BAG - Bundesamt für Gesundheit. Webpage of the Federal Office of Public Health FOPH 2020; https://www.bag.admin.ch/bag/en/home.html.

5. Schweizerische Eidgenossenschaft - The Federal Council. Coronavirus: Federal Council bans large-scale events 2020; www.admin.ch/gov/en/start/documentation/media-releases.msg-id-78289.html.

6. BAG - Bundesamt für Gesundheit. Communicable Diseases Legislation - Epidemics Act, (EpidA) 2020; www.bag.admin.ch/bag/en/home/gesetze-und-bewilligungen/gesetzgebung/gesetzgebungmensch-gesundheit/epidemiengesetz.html.

7. BAG- Bundesamt für Gesundheit. Coronavirus: Federal Council declares 'extraordinary situation' and introduces more stringent measures 2020; www.bag.admin.ch/bag/en/home/dasbag/aktuell/medienmitteilungen.msg-id-78454.html.

8. BAG - Bundesamt für Gesundheit. Federal Council to gradually ease measures against the new coronavirus 2020; www.bag.admin.ch/bag/en/home/das-bag/aktuell/medienmitteilungen.msg-id-78818.html

9. MaisanoF, Bäker A, Taramasso M, Jenny B, Vicentini L, Jenkins V et al. The Certificate of Advanced Studies (CAS) course adapted to a pandemic. Eur Heart J 2020; 41:1716-1718

10. Gesundheit, B.-B.f., Situation Schweiz und international. 2020.

11. Salathe M, Althaus CL, Neher R, et al., COVID-19 epidemic in Switzerland: on the importance of testing, contact tracing and isolation. Swiss Med Wkly 2020;150:w20225 doi: 10.4414/smw.2020.20225..

12. Schweizerische Eidgenossenschaft - Bundesamt für Statistik. Bevölkerung,. 28.03.2019; https://www.bfs.admin.ch/bfs/de/home/statistiken/bevoelkerung/stand-entwicklung.html.

13. Schweizerische Eidgenossenschaft - Bundesamt für Statistik. Herz- und Kreislauf-Erkrankungen,. 16.06.2020; https://www.bfs.admin.ch/bfs/de/home/statistiken/gesundheit/gesundheitszustand/krankheiten/herzkreislauf-erkrankungen.html.

14. Schweizerische Eidgenossenschaft - Bundesamt für Statistik. Spitäler,. 16.06.2020; https://www.bfs.admin.ch/bfs/de/home/statistiken/gesundheit/gesundheitswesen/spitaeler.html.

15. Wilhelm MJ, Ruschitzka F, Flammer AJ, et al., Outcome of inter-hospital transfer of patients on extracorporeal membrane oxygenation in Switzerland. Swiss Med Wkly 2019; 149:w20054 doi: 10.4414/smw.2020.20192.

16. NZZ - Neue Zürcher Zeitung. St. Gallen will seine eigene Herzchirurgie,. 20.02.2018; https://www.nzz.ch/schweiz/st-gallen-will-seine-eigene-herzchirurgie-ld.1358723.

17. WHO - World Health Organization. Italy Situation 2020; https://covid19.who.int/region/euro/country/it.

18. BAG - Bundesamt fur Gesundheit. COVID-19 in der Schweiz 2020; https://covid-19schweiz.bagapps.ch/de-1.html.

19. BFS - Bundesamt fur Statistik. Spitaler - Infrastruktur/Beschaftigung/Finanzen. 2018; https://www.bfs.admin.ch/bfs/de/home/statistiken/gesundheit/gesundheitswesen/spitaeler/infrastrukturbeschaeftigung-finanzen.html.

20. $\quad$ FMH - Foederatio Medicorum Helveticorum. FMH-Arztestatistik 2019; https://www.fmh.ch/themen/aerztestatistik/fmh-aerztestatistik.cfm\#i131905.

21. Tan C, Dean LS. Conscious sedation for TAVR: A wave of the future? Catheter Cardiovasc Interv 2018; 91:343-344.

22. EuroELSO - Euro Extracorporeal Life Support Organization. EuroECMO-COVID Survey 21 June 2020. https://www.euroelso.net/inhalt/uploads/2020/06/Map-2020-06-21.pdf. 
23. Schmiady MO, Sromicki J, Kucher N, et al. Successful percutaneous thrombectomy in a patient with COVID-19 pneumonia and acute pulmonary embolism supported by extracorporeal membrane oxygenation. Eur Heart J 2020; May 12:ehaa403. doi: 10.1093/eurheartj/ehaa403.

24. Alshahrani MS, Sindi A, Alshamsi F, et al., Extracorporeal membrane oxygenation for severe Middle East respiratory syndrome coronavirus. Ann Intensive Care 2018; 8:3.

25. Noah MA, Peek GJ, Finney SJ, et al., Referral to an extracorporeal membrane oxygenation center and mortality among patients with severe 2009 influenza A(H1N1). JAMA 2011; 306:1659-68.

26. GOV.UK - Public Health England. Guidance Considerations for acute personal protective equipment (PPE) shortages 18.06.2020; https://www.gov.uk/government/publications/wuhan-novel-coronavirusinfection-prevention-and-control/managing-shortages-in-personal-protective-equipment-ppe.

\section{Hosted file}

20200730-JOCS-COVID-19-Swiss perspective-Figure 1.docx available at https://authorea.com/ users/345115/articles/473375-covid-19-the-swiss-perspective

\section{Hosted file}

20200730-JOCS-COVID-19-Swiss perspective-Table.docx available at https://authorea.com/users/ 345115/articles/473375-covid-19-the-swiss-perspective 